Literatura y Lingüística $\mathrm{N}^{\circ} 25$

ISSN 0716-5811 / pp. 61-81

\title{
Marco Denevi en la década de los ochenta. Literatura y política*
}

\author{
Nicolás Abadie**
}

\section{Resumen}

Con la vuelta de la democracia en Argentina en 1983, comienzan a circular discursos de lo más diversos que tenían como objeto de análisis las causas sociales y políticas que motivaron el último golpe de Estado. Dentro de esta eclosión de objetos literarios, encontramos ficciones que indagan en el modelo de país que se aspiraría a construir y otras que anticipan el futuro de la nación a través de la lectura de los acontecimientos que sucedían en ese momento. Marco Denevi (1922-1998) en esta década incorpora a su particular modo de entender la literatura el rol determinante de la política. Después de haberse iniciado en el relato policial, creado minificciones, escrito piezas teatrales y novelas de gran mimetismo con la clase media argentina, en las obras publicadas en los 80 buscará encontrar las causas del fracaso de esa "anomalía histórica" que se dio en llamar Argentina, sobre todo en la predisposición sicológica y el carácter del porteño rioplatense.

Palabras clave: literatura y política, Marco Denevi, novela histórica y de anticipación

\section{Marco Denevi in the decade of eighties. Literature and politics}

\section{Abstract}

With the return of the democracy in Argentina in 1983 they begin to circulate several speeches that took as an object of analysis the social and political reasons that motivated the last military dictatorial government. Inside this great manifestation of literary objects, we find fictions that investigate the model of country who would aspire to construct and others that anticipate the future of the nation across the reading of the events that were happening in this moment. Marco Denevi (1922-1998) in this decade incorporates into his individual way of understanding the literature the determinant role of politics. After writing has begun in the police statement, created minifictions, theatrical pieces and novels of great mimetism with the Argentine middle class, in the works published in the 80 it will seek to find the reasons of the failure of this "historical anomaly" that was given in calling Argentina, especially in the psychological predisposition and the character of the argentinean people.

Key words: literature and politics, Marco Denevi, historical novel and of anticipation

Recibido: 16-12-2011 Aceptado: 23-01-2012

* $\quad$ El presente trabajo se inscribe dentro del proyecto de investigación doctoral: "Voces y actores sociales en la narrativa de Marco Denevi. El examen del nacionalismo a través de la ficción de oralidad”, aprobado por el Comité Académico -res. 380/04- del Doctorado en Letras de la Facultad de Filosofía y Humanidades y por el Consejo Superior -res. 424/04- de la Universidad Nacional de Córdoba.

** Licenciado en Letras, Magíster en Literatura Mexicana. UNC-CONICET, Argentina. abadie_nd@ yahoo.com.ar 


\section{Una semblanza}

Marco Denevi (1922-1998) era un escritor singular. Su posición ante el campo literario argentino fue ambigua. A partir de 1968, con dos novelas reconocidas a nivel internacional -Rosaura a las diez, premio Kraft en 1955 y Ceremonia Secreta, premio Life en 1960- se dedica de lleno al oficio de la escritura, renunciando a su empleo en la Administración Pública, camino que lo conducirá a formar parte de la Academia Argentina de Letras. No obstante, prefirió mantenerse en la periferia del ámbito intelectual, desplazándose en los márgenes que supo construir.

De no ser por lo enigmático de su figura, este introito no sería necesario.

\section{A modo de introducción}

La escritura de Denevi es ejemplo de una literatura que dialoga con lo social. Desde su opera prima se puede notar la presencia decisiva que el lenguaje oral tiene en la narración. Las distintas imágenes que de Rosaura configura el lector no son sino retratos hablados, representaciones ${ }^{1}$ -las más de las veces inacabadas- que realizan los individuos de tal o cual clase o condición y que discursivizan de manera no inocente. Esta multiplicidad de puntos de vista en la reconstrucción del crimen, de tradición literaria estadounidense -entiéndase W. Wilkie Collins- se complementa con mecanismos textuales de marcada innovación. Por ejemplo, la sustitución de identidades. Rosaura no existe como tal, sino que es una entelequia ficcional que los habitantes de La Madrileña quieren ver materializada en la imagen de una mujer de la calle, aunque Camilo Canegato, el presunto victimario, confiese su virtualidad:

-Sí, usted dice un sueño, un fantasma, pero lo que hay allá en la morgue parece de carne y hueso.

-Je, je, yo no sé lo que usted tiene en la morgue. Yo le hablo de Rosaura. Rosaura sí es una pura invención mía, una pura creación mía. Rosaura me pertenece enteramente. Yo le di nacimiento, le

1 En una definición libre, entendemos por representaciones a las construcciones colectivas, de las instituciones, de los medios, de los imaginarios, mediante un proceso de acumulación de signos y elementos heterogéneos que se le adosan, modificándole no solo el significado sino $y$, sobre todo, el valor, ya que remiten a ideologías diversas en tanto cada uno responde a una instancia de producción dada. 
di vida, forma, rostro, nombre. Yo pude hacerla desaparecer. (Denevi, 1975:184)

A este rasgo habría que añadirle el manejo sutil del humor local, la sicología extravagante de los personajes configurados y la decisiva presencia de otros géneros discursivos -el epistolar, fundamentalmente-en la dilucidación del crimen.

[Extracto de la Carta de María Correa que, con una nueva cédula de identidad, pasa a llamarse Marta Correga a Rosa Chinca]

La Iris, media borracha, se levantaba torpemente de la cama. Estaba sola. Sola y borracha ¿me comprende tía? ¡Ah, perra! Me abalancé sobre ella, que al oir ruido se dio vuelta. Me vio, puso cara de estúpida e intentó meterse otra ves en la cama. Pero ya era tarde. La china es pura grasa. Con ella son inútiles las bofetadas y los arañasos. No los siente. Le resbalan. De modo que decidí tomarla de las mechas, y asi, como quien revolea a una gallina, con una fuersa que no se de donde me salía, la tiré al suelo y la pisotié furiosamente, como lo que es, como una alimaña, hasta desacerla...la Iris, tendida en el suelo, perdiendo sangre por la boca, parecía muerta... hui... no se por donde anduve. Solo que caminé mucho. Anochecía... y fue allí, tia, allí sentada en la Plasa Once...cuando me acordé de el idiota: Camilo Canegato...me fui para La Madrileña... una china con aspecto de mucama salió a atenderme...y en eso un mundo de gente salió del interior de la casa y vino a mi encuentro, gritando, riendo y llamandomé Rosaura (227-229)

Metodológicamente, creemos pertinente aclarar que entendemos que, dentro del abanico de posibilidades que disemina la obra literaria como signo puro (Bessière, 2002:357), es posible tensionar los alcances de la mímesis aristotélica en tanto «representación literaria, que presupone la existencia previa e independiente de los objetos a los cuales el texto refiere», y considerar al realismo como un efecto producido en y por el texto, que tiene como fin, en palabras de Todorov, «disimular cualquier regla y darnos la impresión de que el discurso es en él mismo transparente, inexistente» (Bessiére, 2002:358).

Este efecto ha de ser una constante en las obras de Denevi y se logra, entre otras cosas, por lo que llamamos ficción de la oralidad. Para Berg (1999:21) «la específica semiosis cultural que atribuimos a la oralidad literaria debe ser considerada siempre como un acto creativo, como la libre elección de elementos significativos que el texto de la cultura pone a 
la disposición del escritor». Y, como se vehiculiza a través del medio de la escritura, se convertiría en un signo más dentro del texto, que se instituye como una «codificación secundaria», según Lotman (1999:164).

Los elementos de la oralidad fueron una variable constante dentro del discurso elaborado en torno de la identidad nacional. Berg (1997:29) recorre la tradición de la oralidad literaria en Argentina, concluyendo en que los textos elaborados sobre las bases de este criterio, «en vez de presentar [la] como elemento de la construcción de una argentinidad coherente, invita[n] al lector a entrar en el proceso de su lectura crítica».

Retomando el hilo conductor, advertimos que lo que adquiere dimensión significativa en la escritura de Denevi es el tratamiento que realiza en torno de la configuración de los personajes. Dentro de esta línea, en las producciones posteriores habremos de encontrar características similares en la manera de diseñarlos, entre las que se destaca el aire de "naturalidad" que encarnan, especialmente por la utilización del lenguaje cotidiano, por lo que se puede inferir que los registros de las diversas voces que aparecen en las páginas, tienen su correlato en las configuraciones sociales y sus tipologías en las que aquellos discursos se insertan.

En lo que a esto refiere, sus cuentos y novelas pueden analizarse como "dramatizaciones" o "escenificaciones" de aspectos de la vida nacional, en las que los protagonistas «son argentinos que bregan por sustraerse del modo de socialización en el que se formaron, oscilando entre el acatamiento del orden y la transgresión, características de la identidad argentina: lo que hicimos no es grave» (Amores, 2006: 260). De tal modo, se pueden apreciar formas de comportamiento de actores que integran diversas clases sociales dentro del panorama nacional. Al mismo tiempo, son estas voces las que examinan la nación por medio de la palabra. Esta actitud ante el texto no hace sino tensionar «los límites entre literatura, género, sociedad y política» (:260) y, creemos, propone una nueva significación a la que se le puede otorgar sentidos sobre todo al problematizar y analizar el entrecruzamiento de esas discursividades.

\section{Del oficio del escritor}

Dos determinismos encasillan la obra de Denevi: la consagración como escritor por medio del cultivo de géneros «menores» y la adopción de sus obras en el nivel medio de enseñanza, consideraciones que no pasan 
inadvertidas por el aparato de la crítica «seria» ${ }^{2}$. En este sentido debemos acordar que, a partir de tales valoraciones, los textos no van a tener esa carga semántica elevada de la que habla Lotman y que les permitiría el ingreso en el círculo restringido del Arte.

Sin embargo, la escritura deneviana no es iniciática ni ingenua; es una escritura de oficio, a tal punto que las obras son sometidas a un proceso de rescritura constante por el mismo autor. Consultado sobre el procedimiento que emplea al escribir, declara:

La escritura es apenas (y nada menos que) el signo gráfico del lenguaje oral. Mientras escribo, no tengo delante de los ojos un texto. Tengo personajes que hablan y que se mueven. Los veo, los oigo. Entre ellos y yo no se interpone el texto como una realidad propia, sino como una materialidad distinta. El texto es un intermediario invisible. Después, cuando terminé de escribir, el texto reaparece ante mis ojos, se me hace visible, se independiza de mí. Y es ahí cuando encuentro las fallas, los errores. (Delaney, 2006:99)

Su biógrafo Delaney advierte que estas correcciones, posteriores a sus obras, rara vez son modificaciones estilísticas, sino estructurales, expansivas, de voces y discursos y, ocasionalmente, mutaciones drásticas.

El compromiso, entonces, tiene que ver con lograr una escritura que se construye desde el lenguaje vivo, el de todos los días, pero atendiendo a la organización interna del texto en el que esa palabra se dice, enclave que acerca su producción a la tendencia posmoderna en la que se tensionan los límites entre la realidad y la ficción.

De este modo, las experimentaciones más audaces se realizan en lo que respecta a la estructura del texto. Continuando con la tendencia de la novela polifónica con la que irrumpe en el ámbito literario en el que más depurados y sólidos cristalizan estos elementos de la poética deneviana es en Manuel de historia de 1985.

2 Marta Molinari (seudónimo de Ismael Viñas) en un artículo publicado en la revista Contorno en julio de 1956 dictamina: «Marco Denevi dice que [Rosaura a las diez] es su primera obra y que la concibió y la escribió en acto de amor sin preocuparse por su ulterior destino. La novela es, por lo demás, un éxito de librería; lo que se llama un best-seller...el caso es que ha sido premiada por un jurado del que formaba parte un crítico literario de veras y algún escritor discreto... que la crítica la ha acogido como si se tratara realmente de un hecho artístico... Denevi ha demostrado tener cierta superficial facilidad de palabra y alguna habilidad técnica para el manejo de un lenguaje que oscila entre la parodia a lo Juan Mondiola y quevedismo seudoborgiano... alguien debería advertirle que no existe en su novela ninguna excelencia que esté más allá de las realizaciones de Hugo Wast o de cualquier discreto fabricador inglés de novelas policiales» Rev. Contorno julio de 1956 n 7-8 pag.55 
Desde un anclaje sociopolítico, Fernando Reati la clasifica en lo que el crítico denomina novela de anticipación ${ }^{3}$, remitiendo a cuestiones argumentales. Pero si nos fijamos en la técnica de composición estamos ante la presencia de una obra múltiple en la que lo que predomina es la escritura en su propia inmanencia. Esto es, la escritura se estructura en su propio sistema cerrando el círculo de la comunicación semiótica, lo que trae aparejado que las categorías literarias consagradas se suspendan y complejicen. Por ejemplo, la de autor es una de las más tensionadas ya que, en este ir y venir cronológico en el que nos sumerge la obra, aparecen nominados varios autores -Ramón Civedé (anagrama del nombre del autor), Sidney Gallagher, Sebastián Hondio y Marco Denevi- con la promesa declarada de haber escrito el Manuel de historia, obra que permanece oculta al lector en la materialidad del texto. Complejidad de voces narrativas que no deja claro dónde comienza y cómo concluye el inicio de la historia como fábula, en un movimiento aglutinante de materias narrativas dispersas.

La estructura rizomática, propuesta por Deleuze y Guatari ${ }^{4}$, está en la base de la obra, compuesta por capas narrativas yuxtapuestas a las que se puede ingresar desde distintas entradas y donde cada uno de los segmentos, aunque heterogéneos, proliferan, entran en contacto y se dispersan. El narrador del fragmento que citamos en lo sucesivo, cumple en la diégesis la función de reconstruir los segmentos discursivos para «empezar a planear la historia de Manuel» (Denevi, 1999:187). La incertidumbre en tratar de nominar a esta función autorial que intenta ordenar el caos, no hace sino complejizar aún más el orden del relato:

Todos esos materiales, que leí o que escuché varias veces, me permitieron deducir que:1) quienes dialogan en el casete son el hombre que lleva el falso nombre de Ramón Civedé y el joven

3 La premonición de que la violencia no se terminará con la llegada de la democracia comienza a afirmarse en "1984" (que corresponde al presente democrático de los primeros años de posdictadura) cuando en un ominoso final se produce la muerte del joven estudiante norteamericano agredido por vándalos en pleno centro de Buenos Aires. En "1988" se anticipan algunos aspectos de la crisis de 1989 (...) el narrador describe un país en virtual caos económico, con comercios saqueados, inflación fuera de control, niños mendigos y jóvenes delincuentes pululando por las calles, mientras los partidos políticos están divididos, la Justicia paralizada y la universidad pública sin recursos (Reati, 2006:42).

4 En la teoría filosófica de Gilles Deleuze y Félix Guattari, un rizoma es un modelo descriptivo o epistemológico en el que la organización de los elementos no sigue líneas de subordinación jerárquica sino que cualquier elemento puede afectar o incidir en cualquier otro (Deleuze $\&$ Guattari, 1972:13). En un modelo rizomático, cualquier predicado afirmado de un elemento puede incidir en la concepción de otros elementos de la estructura, sin importar su posición recíproca. El rizoma carece, por lo tanto, de centro. 
que se hace llamar Sidney Gallagher; 2) Sidney Gallagher escribió el relato titulado "1996" y Ramón Civedé, el que atribuye a Sebastián Hondio, y 3) "Manuel de historia" quedó inconcluso y, por lo que sé, inédito, porque el 16 de diciembre de 1984 Sidney Gallagher murió desangrado en la calle Florida.

Ahora alguien me enviaba estas piezas sueltas con el obvio propósito de que yo armase un libro y lo publicase. Mal o bien lo he hecho. He hecho más: por mi cuenta y riesgo les añadí un texto que me pertenece, que inspirándome en George Orwell titulé "1984" y que creo necesario para la mayor comprensión de los demás trozos. (Denevi, 1999:183)

La obra literaria, a través de este procedimiento, se deconstruye y ya no es portadora de un sentido pleno y un único significado. En este tipo de literatura que propone Denevi, la escritura no es vehículo del mensaje, sino que es el mensaje. Si dejamos de pensar en la tradicional dicotomía que analiza el discurso literario, teniendo en cuenta el qué y el cómo de la expresión, en este caso el cómo es el qué, como ilustra Prada Oropeza.

De acuerdo con estas consideraciones, la narrativa de Marco Denevi debería describirse en un lugar otro del que fue asignada. Convergen en sus novelas un lenguaje ágil, transparente, cotidiano, hecho de palabras comunes y en un registro en el que reconocemos una identidad local con procedimientos escriturales propios del círculo restringido de la literatura, tanto nacional como universal. La escritura utiliza la lengua como materia prima. En Denevi esta materia que quiere ser modelada, es la que se dispersa en los espacios urbanos, conglomerado de prácticas lingüísticas diversas, de miscigenaciones constantes.

La literatura de Marco Denevi irrumpe en el campo literario junto con la encrucijada política histórica del peronismo, que sacudió los cimientos progresistas e ilustrados que venían modelando la imagen de un país "visible" para el resto de las naciones, oponiéndose a un país "invisible" que estaba tomando conciencia de su rol.

Ante la confusión y el ruido, propios del babilonismo que estalló en 1945 y se fue silenciando, sangrientamente, en las décadas posteriores y en una coyuntura en la que se restituyen los canales de comunicación, no es casual que Denevi, como hijo de inmigrantes, como porteño quisiera «devolver o dar al idioma de los argentinos, la precisión, el ajuste, la formulación directa, y no primaria entre idea y expresión, escrita y oral» (Polleti, 2004:13). Este sentido es el que determina que 
sus obras sean portadoras de un lenguaje multiforme y dinámico, para expresar por medio de la ironía un «sacudimiento sobre los prejuicios, las falsedades, las hipocresías y falacias de los hombres y sus obras; una constante demolición de subcultura, oficialismo, demagogias, modas, extranjerismos, esnobismos, en fin, el constante ataque a la estupidez entronizada y atascante» (14).

\section{De la historia nacional}

La rescritura de la historia en Denevi es un motivo estructural que persigue un fin lúdico al momento de elaborar el objeto, desde la degradación y la incongruencia. En este sentido, la configuración de los personajes, de corte netamente imaginativo, son situados dentro de un contexto de acontecimientos históricos conocidos, a través de una mirada humorística que, en ocasiones, raya los límites de la parodia, la sátira y la ironía.

Enciclopedia secreta de una familia argentina ${ }^{5}$ (1986) subvierte los cánones del discurso histórico oficial -que sirve de material para la composición de los procedimientos caricaturescos- y propone una intencionalidad "chabacana", a través de la cual se manifiesta la calidad de "simulacro del simulacro" de la ficción, con respecto de la narración histórica.

El carácter burgués de la novela histórica y, por lo mismo, la actualización de los constructos históricos que esa visión otorgó al imaginario colectivo son patrimonio intelectual en Denevi, pero, al mismo tiempo, son tópicas textuales en las que media el discurso literario como artefacto. Esto es, un narrador, en ocasiones cronista, se propone contar el desarrollo de la historia familiar de los Argento, a través del relato que realizan los personajes de la vida y obra de sus antepasados retratados al óleo.

El histórico es un discurso que sirve de "muestrario" de las cualidades de la familia. Así, en el comedor de la mansión familiar asistimos al desfile de los sucesivos ancestros, descriptos casi como próceres. Siete

5 En la advertencia preliminar del autor que encabeza la edición de 1998, aquélla de «título pretencioso y estructura caótica... estimuló la entusiasta indiferencia del público» por lo que se le ha «rebajado el título, atemperado el caos y extirpado no pocas páginas superfluas afectadas de inflación». El resultado, Una familia argentina, mutación genérica de miscelánea a novela, intenta reflejar, «mediante deformaciones paródicas, caricaturescas y a menudo irreverentes, algunas de nuestras realidades». 
Manueles, pretendida encarnación de UN solo Manuel, ejemplifican las generaciones que fueron testigos de los acontecimientos más importantes de la historia nacional.

En orden cronológico, el primero de los Manueles personifica al pícaro de la tradición literaria española, al mismo tiempo que a la clase advenediza que se subió a las carabelas del descubrimiento. A través del segundo Manuel, recorremos la historia del Virreinato del Río de La Plata, contexto socio-histórico que sirve como telón de fondo en la representación de los distintos grupos humanos que se desarrollaban en el momento y que la historiografía tradicional describe.

Centremos nuestra atención en Manuel III como personaje que se desempeña dentro del marco de la Revolución de Mayo de 1810. Cabe mencionar que en la estructura de la novela, esta primera parte visita la cronología de la historia nacional hasta la batalla de Caseros (1852), momento en el que

Manuel Rosales fue desalojado del gobierno por uno de sus antiguos correligionarios (...) y se convirtió él mismo en emigrado a la Inglaterra, el Peregrino de la Nueva Troya regresó a la ciudad, se calzó el nimbo de Mártir de la Tiranía y exigió un cargo en el Gobierno. Le proporcionaron el de delator de partidarios del régimen depuesto, al primero que delató fue al Mazórquido, y el Mazórquido tuvo que recibir las descargas del fusilamiento". (Denevi, 1998:113)

Adviértase en la cita anterior que la propuesta de Denevi consiste en leer en clave el juego de nombres propios, toponímicos y patronímicos, cuya deformación humorística tiene como co-relato un referente convencionalmente acordado. Intención que, inferimos, intenta darle otra vuelta de tuerca al modo de narrar la Historia.

La fundación de la familia se fecha solemnemente el Anno Domini MDCCCLIII y no podía ser de otra manera, ya que, caído el rosismo, se inicia el ascenso al gobierno de sectores que estructurarían el Estado nacional en aras de la modernización y el progreso, ostentando el poder legítimo afirmado en las «derrotas de las disidencias provinciales» (Terán, 2008:110).

Dos líneas interpretativas podemos derivar de este juego de nombres. En primer lugar, la inclusión de la imagen de Rosas dentro de la corriente del revisionismo histórico que Halperín Donghi sitúa en los inicios de la década de 1930, y que tuvo como motivos centrales el «repudio de la 
democratización política que entrega al país a dirigentes con la habilidad para organizar máquinas electorales no solidarias con los intereses de la nación» (Halperín Donghi, 2005:16-17) y la denuncia del modo de inserción de la Argentina posindependiente en el panorama mundial, al mismo tiempo que critica la incapacidad de las clases dirigentes para llevar a cabo el proceso político argentino, y actualiza la imagen del caudillo como "mediador" entre las masas populares y las elites gobernantes. Por supuesto que, para los Argento, la mirada que se reproduce es aquella que delinea la imagen de un dictador, aunque mofándose de sus cualidades y atributos (Cfr. Denevi, 1998:111-113).

En segundo lugar, el nombre establece relaciones intertextuales con Manuel de historia, novela inmediatamente anterior que, para los fines que nos ocupan, enuncia como enfermedad endémica de los argentinos el manuelisma, especie de trastorno que consiste en la negación del presente, la mitologización del pasado y la añoranza de un futuro utópico.

La historia que se escribe después de Caseros, los actores, las situaciones y los hechos que se recortan son orgullo de la familia Argento, tilingos que imitan la manera de ser aristocrática, que avienen con la visión "progre" de la sociedad civil, por más que tuvieran que quedarse en la mansión ubicada entre las calles Humberto Primo y Defensa del barrio de San Telmo, abandonada durante la epidemia de fiebre amarilla que obligó al éxodo de la "gente bien" hacia los barrios del norte de la ciudad.

Aclarando los tantos, el guarango es la contracara del tilingo, dice Jauretche. Tengamos en cuenta, ineludiblemente, que el guarango es un "tipo" dentro de nuestra conformación social. Partamos de la conclusión: el guarango sería una especie de "ente" en el que "hay potencialmente lo que puede ser» (Jauretch, 2007:19). Una promesa ad futuro podríamos decir. Si seguimos tratando de describir sus características, la relación jauretchiana nos dice que es un consentido, satisfecho de sí mismo y exultante de esa satisfacción, alguien que pisa fuerte, porque tiene donde pisar, un producto directo del imperio, convenimos. El tilingo carga con el guarango como una desgracia nacional, lo irrita. Pero

[...] también irrita al guarango los guarangos que ya son importantes. Entonces se juntan los guarangos importantes con los tilingos (...) tilingos y guarangos unidos contra los otros guarangos terminan por mezclarse y se vuelven contra el país que no es guarango ni tilingo. Y ésa es la explicación psicológica de algunas revoluciones (...) Es la oportunidad que aprovechan 
algunos guarangos que han pelechado con la prosperidad del país para pasar a ser tilingos. [Tilingos y guarangos] se cruzan en las revoluciones. De ese cruce suele resultar un híbrido: el tilinguarango [que aplaude y hace comentarios]. Y todo el problema es meter en cintura estos dos neoplasmos de la cultura argentina". (Jauretche. 2007:19-20)

La extensa cita de Jauretche, permite que ingresemos a diversos territorios conceptuales. En primer lugar, como categoría descriptiva podríamos tratar de "leer" la posición de Denevi dentro o fuera de su alcance. En segundo lugar, y en este apartado específicamente, nos incumbe abordar otro de los grandes campos que se imbrican en la obra y que tiene que ver con el uso del humor, en sus diversas manifestaciones. Con esta configuración el autor se acerca a la Historia.

Pablo de Santis ${ }^{6}$ se encarga de analizar el uso que determinadas narraciones argentinas hicieron del humor. Visualizando la manera en que los autores trabajan sus dos objetivos básicos -el primero consistiría en fundar una especie de complicidad con el lector, reclamando su atención sobre los mecanismos secretos del mundo, lo que se puede resumir en exhibir; el segundo pretende consolidarse en la búsqueda de verosimilitud, distrayendo los efectos de la ficción, o en otros términos, esconder- reconoce dos líneas fundamentales. Una primera línea aborda lo que tiene que ver con la crítica a las costumbres y a los lenguajes. Consiste en inventar una voz para contar o describir una época o un instante con la deliberada intención de poner algo en descubierto, una inconsecuencia, una ridiculez, un renuncio; así el humor es político porque atestigua. La segunda línea se corresponde a la utilización del humor conceptual, inteligente, ingenioso, simbólico, absurdo que es la que dominan Marcedonio Fernández y Leopoldo Marechal por extraer algunos ejemplos de la fuente.

Podríamos hacer coincidir ambas tendencias en la intencionalidad crítica o de "sospecha" que significaría la manera insidiosa - o suspicazde analizar un acontecimiento, lo que no dejan de ser sino diferentes lecturas y elecciones que se hacen frente a una ley: conversa -elige y lee el camino recto: la política de derecha-, perversa -invierte los términos: la política de izquierda-, subversiva o irónica -pregunta a la pregunta-y reversiva -pregunta a la respuesta, la del humor o "libertaria"-7.

6 "Risas argentinas: la narración del humor" en Historia crítica de la literatura argentina. Vol.11. Emecé. 2000. Pp. 493-510.

7 Ver Ana B. Flores. Políticas del humor. Ferreyra editor. Córdoba. 2007. 
Marco Denevi en la década de los ochenta. Literatura y política / Nicolás Abadie

Denevi configura la lectura que de la Revolución de Mayo realizan los Argento, tilingos "importantes" que modelan el retrato de un tilingo mayor partícipe de los acontecimientos de 1810. Los artificios literarios, a lo largo de la obra, se utilizan con el fin de indagar qué ha sido de esa estirpe de tilingos que ha visto el inicio de su descrédito el 17 de octubre de 1945, desde una perspectiva móvil que no deja de reflejar aspectos de ambos tipos de la dicotomía jauretchiana.

Dejemos hablar a la ficción. Describe el narrador: «el óleo de la pinacoteca iconográfica le adjudicaba el porte austero del filósofo, la mirada iluminada por el ideal y la fisonomía serena del patriarca» (Denevi, 1998:72). El sujeto desinencial, es Manuel III, muerto vivo. Este Manuel cumple la función de "actuar" de muerto en los velorios improvisados por los Conspiradores -"doctores" de alcurnia, leídos y seguidores del "ateo de Ginebra" y del "lobo Hobbes"- con el fin de obtener información para dar el golpe que derroque al virrey en el Río de La Plata. Quien aborde la obra del escritor reconocerá la intertextualidad explícita con Los asesinos de los días de fiesta (1972) referida a lo argumental.

Una manera de entender la parodia, desde su sentido etimológico -"estar junto a..."-, es aquella que nos remite a una figura retórica que consiste en establecer un paralelismo, un seguimiento, una persecución, o una imitación de un referente ${ }^{8}$. Así, en este caso, el discurso parodiante ha de establecer dos objetos parodiados: el primero tiene que ver con la historia de la familia y su desarrollo, hasta su caída provocada por el «aluvión de retazos de hombres y de mujeres, cabezas, troncos, y miembros sueltos, aunque entreverados en una misma masa informe» (Denevi, 1998:282); el segundo se corresponde con aquellos relatos de la Historia que protagonizan los antepasados.

Los conspiradores que preparan la Revolución no son sino la deformación de los integrantes de la Primera Junta de Gobierno. Se hacían llamar los "nueve", en primera instancia, luego los "chuquisacos" y finalmente integrantes de la Logia Termidor. Felipe Pereyra, Gervasio Torralba, Sofanor Carabajales, Julián Altamirano, Vizcaíno Illanes, Ignacio Campuzano, Egido Valluerca, Elías Benjuí, Crisóstomo Camesilla son el correlato de Saavedra, Moreno, Paso, Belgrano, Castelli, Alberti, Azcuénaga, Larrea, Matheu.

8 Pablo de Santis. Op.cit.: 501.

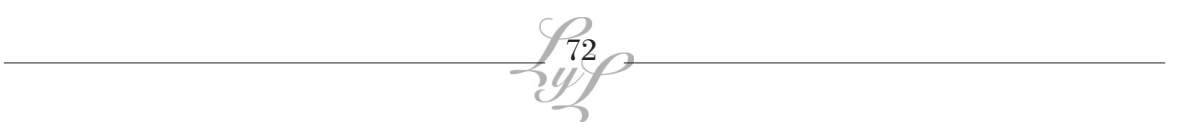


Tratando de establecer otro tipo de conexiones en estas relaciones in absentia de la ficción con la historia, es decir, buscando indicios que pudieren emparentar nombre con personaje histórico, tres de los integrantes pueden ser representaciones más o menos identificables. Felipe Pereyra es Mariano Moreno, Ignacio Campuzano es Alberti y Elías Benjuí pudiera representar a Matheu. Estos indicios tiene que ver con datos específicos dados por la historia: doctorado en Chuquisaca, Pereyra, al igual que Moreno, representa el ideal de la Junta; Campuzano es sacerdote y Benjuí una especie de modisto9 .

Otra línea posible de interpretación es la que establece la mutación de los nombres de los chuquisacos: Felipe Pereyra pasó a llamarse Felipe Igualdad; Gervasio Torralba, Gervasio Libertad; Sofanor Carabajales, Sofanor Fraternidad, y los restantes mudaron sus "aborrecibles apellidos españoles" por Ventoso, Pluvioso, Nevoso, Brumario, Germinal y Pradial (Denevi, 1998:62). El correlato directo lo hallamos en los principios defendidos por la Revolución Francesa en los primeros, y en los nombres de días y decenas de días correspondientes al Calendario Republicano de 1792 que los jacobinos propusieron como alternativa al Calendario Gregoriano y que tuvo vigencia hasta 1806, en el resto. Al mismo tiempo, Termidor refiere a la época en que se produjo el levantamiento francés de acuerdo con este Registro.

Los girondinos, ala más moderada de la Convención Nacional, eran revolucionarios republicanos de carácter moderado que representaban los intereses de la alta burguesía, proponiendo como sistema de gobierno una monarquía constitucional. Los "nueve" se hacían llamar, además, giróndinos, acentuándolo "a la francesa", excusa argumental para identificar que, en las tierras del Plata, la revolución trasplantada fue ideada por una minoría ilustrada como corresponde a una sociedad de castas $^{10}$. En el mismo sentido se interpreta el latinoamericanismo defendido por los chuquisacos e incluido en el supuesto epistolario que Manuel III mantuvo con Francisco Miranda y Simón [Rodríguez] Carreño y que los tilingos lamentan no conservar.

Esta propuesta distorsiva pone de manifiesto la crítica a un presunto carácter improvisado de la gesta de Mayo y a la falta de una propuesta programática sólida, ya que de lo que se trató fue de «hacer revolución

9 Cfr. Felipe Pigna. 2004. Los mitos de la historia argentina. La construcción de un pasado como justificación del presente. Tomo I. Norma. Bs.As. pp.217-252

10 "Argentinos" designa a los habitantes (no a los nativos) criollos y españoles de Buenos Aires. (Terán, 2008:18) 
francesa en Buenos Aires; sino guillotinar, porque guillotina no tenían a mano... fusilar al menos al virrey: instalarse en el Fuerte y desde allí dirigir los destinos del Río de La Plata y acaso de las Américas» (Denevi, 1998:61).

Los conspiradores fueron realizando sus operativos: organizaban funerales en distintos sectores de la ciudad portuaria, hasta que se anoticiaron de que una Junta de ciudadanos destituyó al virrey y se declaró el Primer Gobierno Patrio. Manuel que, en ese momento estaba cumpliendo su rol, al quedarse solo prolonga su actuación por un tiempo hasta que decide retirarse.

El estado de revulsión social vuelve a la normalidad. El escenario descrito de la vida porteña no ha cambiado en nada. Son las estampas de un manual que se narran como telón de fondo

Las mulatas iban al río a lavar la ropa de sus amos. Por las calles discurrían los vendedores de queso de Goya, de pasteles fritos, de azúcares de agua. Rodaban las carretas altas como castillo con su gauderio sentado en el pértigo. Dentro de los cafés y pulperías los parroquianos perpetuaban naipes, aguardientes y conversación... Las campanas de la iglesia convocaban a misa. Pasaban mendigos a caballo y a pie, pasaban manadas de reses vacunas camino del matadero, pasaban jaurías de canes sarnosos. Desde los charcos llegaba la marimba palúdica de las ranas. Y por ninguna parte las señales del fuego, los rastros de las matanzas, la sombra terrible del patíbulo, el árbol de la horca. (Denevi, 1998:69)

La Revolución había pasado, pero no llegó ni a "revolú". Los nueve cofrades se asimilaron dentro del "sistema" como consejeros de despacho, secretarios rentados de una "Asamblea de los Pueblos Libres" que no se reunió nunca, capitanes y coroneles adscriptos a oficinas de correspondencia y aprovisionamiento.

Los guarangos se fusionaron con los tilingos, los tilingos se hicieron guarangos y a Manuel, al contemplar al Presidente de la Junta Patriótica revestido de terciopelos coloniales y a su consorte cubierta de sedas y de joyas del Virreinato, le sobreviene una risa "perseverante" que le duró un año. Mientras tanto, la Historia como nación independiente comenzaba a escribirse.

Los elementos discursivos que propone el texto deben ser actualizados por el lector desde su circunstancia. Este modo de representación humorístico implica, casi siempre, «la construcción en el texto de una

14


representación de la coyuntura, de algo "actual" y "político"...precisa crear un elemento que sea posible pensar como coyuntural más allá de que sea "verdadero" o "falso"» (Zubieta, 1995:87). La ausencia de una explicación lógica ante una práctica frecuente en la vida política argentina, es lo que provoca la desesperanza y el desequilibrio emocional del protagonista de la ficción y la connivencia del lector.

No obstante, los Argento sostienen la versión que hace de este Manuel un artífice ideológico fundamental en el nacimiento de la Patria. «No movían un dedo sin consultarlo antes, ... pero en secreto y a altas horas de la noche, para quedarse después con toda la gloria. Murió pobre y olvidado, tal como es el triste destino final de nuestros prohombres» (Denevi, 1998:72).

\section{Del análisis político}

Las obras publicadas entre 1985 y 1989 abordan como tema central la cuestión de la argentinidad. Reparemos en la coyuntura política en la que se circunscriben los textos. Manuel de historia, aparece el mismo año en que comienza el juicio a las juntas militares, por las violaciones sistemáticas a los derechos humanos cometidas en la última dictadura. El ensayo literario La República de Trapalanda (1989) circula en momentos de hiperinflación, saqueos a supermercados y desilusión colectiva, que motivaron la renuncia de Alfonsín y la inmediata aplicación de las medidas neoliberales más ortodoxas.

En este sentido, es cómo se puede interpretar el pesimismo y la visión decadentista de la realidad nacional, sobre todo en lo que respecta a la debilidad de las instituciones políticas, garantes de la vida democrática. Entrevistado en ese entonces, al país, dice Denevi, «lo veo como a un niño al que lo tuvieron atado a la pata de una mesa durante años, sin dejarle leer más que historietas. Ahora lo soltaron, pero todavía le falta mucho para que aprenda qué hacer con su liberación» ${ }^{11}$. Tengamos en mente esta declaración porque es a través de este "itinerario metaforizador" la manera en que se irá analizando el ser nacional.

Denevi tratará de explicar las causas del fracaso analizando la estructura psicológica del individuo. En La República de Trapalanda (1989) el examen sobre la realidad nacional se manifiesta de manera directa a

11 Bernardo Neustadt. "Entrevista a Marco Denevi y Osvaldo Soriano". Rev. Extra. Año XXII. $\mathrm{N}^{\circ}$ 260. Febrero de 1987 
través de un enunciador sujeto -un extranjero que observa e interpreta la Argentina del momento-. Desde el inicio se nos aclara que el término Trapalanda es una síncopa de Trapalalanda que significa "tierra de trápalas". Como adjetivo éste refiere a una persona dueña de «una verborragia sin fundamento ni sustancia cuando no decididamente embustera» (Denevi, 1997:7). Por lo tanto, la República descrita remitiría a un «país donde se habla mucho y se miente mucho». En las crónicas del Descubrimiento, Trapalanda era la tierra que se situaba en el sur del sur, entre Tierra del Fuego y el estrecho de Magallanes. Un lugar legendario y mágico que alimentó de embustes, enredos, chismes y engaños a la mente de los conquistadores, lugar donde estaría la Ciudad de los Césares o la Tierra de la Trampa.

Charlatanes y mentirosos, como los gitanos y los políticos, que los argentinos no se indignen -advierte Denevi- es el determinismo genético -herencia de españoles e italianos, "pueblos reacios al laconismo"- lo que nos dota de buena labia. Y esta propensión especulativa fue puesta al servicio de la imaginación para darle forma a los mitos y a las fábulas que, dada la concentración de los habitantes en las grandes ciudades, pertenecieron más al reino de Ariel que al de Calibán. «Trapalanda vendría a ser la Utopía que nos propusimos como modelo» sentencia Denevi (1997:8) y «hemos pretendido vivir como si ya poblásemos la Utopía de nuestras ensoñaciones y de nuestros discursos». Distorsión de la realidad que escribió gran cantidad de páginas en nuestra tradición literaria.

El recurso de esconder la voz enunciativa detrás de la figura de un narrador extranjero que da cuenta de sus interpretaciones permite tomar distancia del objeto descrito. La experiencia de este "huésped enamorado" que se siente como en casa debido a la presencia de un número considerable de inmigrantes, se remonta a principios de 1984 , los primeros meses del camino hacia la reconstrucción de la legalidad. No es casual la fecha. Restituida la democracia, vuelven al país muchos de nuestros intelectuales exiliados y comienzan los esfuerzos por tratar de reconstruir una identidad nacional que se ve como pulverizada y fragmentada en cientos de pedazos.

Las primeras impresiones o, en otros términos, diagnósticos, van a ser el leit motiv de la Teoría que luego se encargará de justificar. Argentina es un país de aventureros, en donde no interesa el trabajo manufacturado y que está signado por la imprevisibilidad. El extranjero dice sentirse un adulto entre adolescentes y se encamina a justificar esta idea.

16


Enumeremos los principales rasgos que reflejan la predisposición sicológica de los argentinos a través de la metáfora del adolescente colectivo.

1. Los jóvenes rara vez saben administrar su patrimonio

2. Sus revoluciones son gestos de rebeldía ante la autoridad familiar

3. No son buenos negociantes; interesan más los frutos que la forma de ganarlos

4. Si el trabajo no incluye el fin lúdico lo invaden la desprolijidad, la mala gana y la irritación y entonces recurre a todo tipo de excusa

5. Lo anterior es causa de la proliferación de los profesionales liberales, los oficios de intermediación, las actividades parasitarias, la política de comité y la burocracia

6. La hipocresía que denuncia en la sociedad es una falta de cinismo

7. Su fanfarronería está hecha de danzas gestuales y de conjuros verbales que trata de cubrir los tembladerales interiores, los miedos, la inseguridad, la delicadeza

8. Necesita del reconocimiento ajeno para confirmar sus propios juicios

9. La sociedad es una feria provinciana caótica y nada limpia, sin reglas de juego, sin técnicas de marketing, con poca y mala tecnología donde compradores y vendedores se engañan y hablan a los gritos

10. El que no piensa como él no sólo está equivocado sino que tiene intenciones malignas

La lista podría ampliarse y polemizarse punto por punto, aunque no pretendemos hacerlo en este lugar. Separándonos de la ficción, en los años de la restauración democrática comienzan a circular discursos que intentan explicar las causas de los vaivenes políticos y sociales del país, al mismo tiempo que proponen distintos modelos de Nación sobre bases ideológicas determinadas.

Denevi, por ejemplo, se declara un "demócrata espiritualista" y considera que la apuesta para una República sólida encuentra sus cimientos en las Instituciones. De extracción burguesa y perteneciente al mundo de la burocracia, antes de dedicarse de lleno al oficio de las Letras, no es casual que su ideario doctrinario se alinee con una política que podríamos identificar como de Centro. Desde esta perspectiva es como entendemos la crítica irónica y mordaz, que se desprende de 
sus obras, al Estado burocrático y a la tilinguería de las clases oligárquicas. Pero, al mismo tiempo, en la antípoda, el concepto de pueblo -que podemos identificar sobre la base de las anteriores descripciones y presente como telón de fondo en sus obras-, se construye por y desde la clase media en particular. Las masas de trabajadores, "descamisados" o "cabecitas negras", son relegados a un espacio periférico, presente siempre sí, aunque restándole presencia activa. De allí las lecturas del peronismo y de las políticas de izquierda, como otro de los tantos mitos y ensoñaciones de la imaginaria Trapalanda en la que el argentino pretende vivir. Como un hechizo, la demagogia del General Perón-dixit-sedujo a las masas, quienes por el precio de un presunto bienestar material perdieron de vista su rol de protagonistas de una empresa política válida.

No es de extrañar, entonces, que Denevi deposite su confianza en el formalismo de las instituciones como "moldes vacíos" en los que la sociedad deberá encauzarse. Recordemos la coyuntura, no sin tomar distancia de la afirmación. La vuelta de la democracia suscitó grandes expectativas, sobre todo en este tipo de escritor que vuelca sus opiniones en los diarios Clarín y La Nación, órganos de difusión de marcada tendencia oligárquica. Los fracasos que se iban previendo se explican por la falta de madurez de un pueblo adolescente. De allí que, ante la crisis hiperinflacionaria, los fragmentos de una sociedad que se quisieron aglutinar hayan ahondado sus grietas. «Hay vastos sectores de la población argentina que han sido marginados no solo de la riqueza material y del enriquecimiento cultural sino también del pacto social cuyo garante es el Poder» (Denevi, 1997:168), sentencia el extranjero que experimenta la vida en la República. Y el Poder debería consolidarse o plegarse a los principios constitucionales redactados en 1853, continúa. La justicia, la paz interior, la seguridad, el bienestar general y los beneficios de la libertad no serán sino aspiraciones mientras que no se procuren los instrumentos adecuados. Hasta el momento entorpecieron ese camino una legislación castradora de los esfuerzos individuales y una burocracia parásita de las economías domésticas.

Muchas líneas de discusión e investigación se pueden desprender de la presente ponencia. Concluyamos, en este espacio, que es el de Denevi uno de los tantos enfoques sobre un objeto que nunca acaba de definirse, porque de eso se trata. El nacionalismo es siempre un proyecto político reivindicativo que «emerge desde una frustración actual o potencial, real o imaginaria», al igual que la identidad es un concepto cuyo significante es procesual pero su contenido es actual. 


\section{Conclusiones}

La posición de Denevi, tanto en lo que respecta al mundo de las letras como al campo de lo político, fue de marcada tendencia liberal. De todos modos, la presencia de las voces que conforman el entramado de lo social está en la base de sus composiciones. Sus ficciones dialogan con estas grandes esferas discursivas en las que se manifiestan diversas interpretaciones en torno de la sociedad, la historia y la política. La presencia de la coyuntura en la que se insertan las obras es determinante en lo que a este aspecto refiere, ya que, restituida la democracia y ante el desafío de reconstruir un pasado inmediato fragmentado y borrado por la dictadura, los textos llevan en sí mismos las huellas de la historia. Lo que no se podía decir en su momento por la censura, a partir de los años ochenta se transforma en bullicio, multiplicidad de voces, de discursos y propuestas estéticas que adquieren visibilidad.

La de Denevi es una ellas. Si bien siempre la presencia de lo social como elemento constitutivo de la obra estuvo presente en su producción, a partir de Manuel de historia, el compromiso político toma dimensiones significativas. No obstante, el foco de interés a lo largo de su trayectoria estuvo puesto en los personajes extravagantes y las situaciones insólitas -a veces absurdas- que se manifiestan en los márgenes del sistema: sujetos desclasados, burgueses venidos a menos, empleados burocráticos, aristócratas desarraigados, voces bastardas que pululan en la noche ocultando su deformidad.

Marco Denevi, a través de un lenguaje dinámico y creativo, da voz a los "anormales", siempre por medio de la mediación paródica y la crítica sutil que oblitera el objeto último al que se dirige: la demagogia burocrática, la vacuidad institucional y la falsedad de las representaciones, poniendo en tela de juicio la fragilidad de un Estado que se diseña desde una concepción imaginaria y no desde las bases sociales. En este sentido, consideramos que su obra debería revisitarse para rescatarla del ostracismo que, deliberadamente, supo construir.

\section{Bibliografía}

Denevi, M. (1974). Rosaura a las diez. Bs. As.: Huemul.

(1986). Enciclopedia secreta de una familia argentina. Bs. As.: Sudamericana.

(1991). Ceremonia secreta. Bs. As.: Corregidor. 
Marco Denevi en la década de los ochenta. Literatura y política / Nicolás Abadie

(1997). La república de Tlapalanda. Bs. As.: Corregidor.

(1998). Una família argentina. Bs. As.: Sudamericana.

(1999). Manuel de historia. Bs. As.: Corregidor.

(2004). Cuentos selectos. Bs. As.: Corregidor.

(2008). Cuentos selectos II. Bs. As.: Corregidor.

\section{a) Bibliografía teórica}

Bajtin, M. M. (2008). Estética de la creación verbal. Bs. As.: Siglo XXI Editores.

Berg, W. (1997). "Oralidad y argentinidad. Contornos de un proyecto de investigación" en Oralidad y Argentinidad. Estudios sobre la función del lenguaje hablado en la Literatura Argentina, Ed. Günter Narr Verlag Tübingen.

Bessiére, J. (2002). "Literatura y representación" en AA.VV. Teoría literaria. México: Siglo XXI.

Cándido, A. (2007). Literatura y sociedad. Estudios de teoría e historia literaria. CCyDEL. México: UNAM.

Deleuze, G -Guattari, F. (2007). Rizoma. Introducción. Coyoacán. México.

Flores, A.B. (2007). Políticas del humor. Córdoba: Ferreyra editor.

Halperín Donghi, T. (2005). El revisionismo histórico argentino como visión decadentista de la historia nacional. Bs. As.: Siglo XXI.

Jauretche, A. (2007). El medio pelo en la sociedad argentina.O.C.vol.3. Bs. As.: Corregidor.

Lotman, Y. (1999). La Semiosfera. Madrid: Cátedra.

Prada Oropeza, R. (1999). Literatura y realidad. México: FCE.

Terán, O. (2008). Historia de las ideas en la Argentina. Bs. As. Siglo XXI.

Zubieta, A. M. (1995). Humor, nación y diferencia. Arturo Cancela y Leopoldo Marechal. Bs. As.: Beatriz Viterbo editora.

\section{b) Bibliografía crítica}

Amores, A. L. (2006). Manual de Lectura Argentina. Hacia una teoría de la lectura. Bs. As.: Ed. Corregidor.

180


De Santis, P. (2000). "Risas argentinas: la narración del humor" en Noé Jitrik (director) Historia crítica de la literatura argentina. Vol.11. Bs.As: Emecé.

Delaney, J.J. (2006). Marco Denevi y la sacra ceremonia de la escritura. Bs.As.: Corregidor.

Molinari, M. «Rosaura a las diez, premio Kraft» en Rev. Contorno. No 7-8. Julio de (1956). Pag.55. Bs.As

Poletti, S. (2004). «El idioma de Marco Denevi», en Denevi, M. Cuentos selectos. Bs. As.: Corregidor.

Reati, F. (2006). Postales del porvenir. Bs. As.: Ed. Biblos.

Saravia, L. (2000). La Argentina en clave de metáfora. Bs. As.: Corregidor. 